\title{
Examining the Pathways Linking Lower Socioeconomic Status and Advanced Melanoma
}

Ricardo A. Pollitt, MD, PhD'; Susan M. Swetter, MD², Timothy M. Johnson, MD³; Pratima Patil, MA ${ }^{4}$; and Alan C. Geller, RN, $\mathrm{MPH}^{4}$

BACKGROUND. Low socioeconomic status (SES) is associated with more advanced melanoma at diagnosis and decreased survival. Exploring the pathways linking lower SES and thicker melanoma will help guide public and professional strategies to reduce deaths. METHODS. The authors surveyed 566 newly diagnosed patients at Stanford University Medical Center, Veterans Affairs Palo Alto Health Care System, and University of Michigan. SES was assessed by education level (high school/general education degree or less [HS], associate/technical school degree, or $\geq$ college graduate). All data was obtained by self-report among patients within three months of their diagnosis. RESULTS. HS-educated individuals were significantly more likely than college graduates to believe that melanoma was not very serious (odds ratio [OR], 2.90; 95\% confidence interval [Cl], 1.79-4.71) and were less likely to know the asymmetry, borders (irregular), color (variegated), and diameter ( $>6 \mathrm{~mm}$ ) (ABCD) melanoma rule or the difference between melanoma and ordinary skin growths (OR, $0.34[95 \% \mathrm{Cl}, 0.23-0.52]$ and $0.26[95 \% \mathrm{Cl}, 0.16-0.41]$ respectively). Physicians were less likely to have ever told HS-educated versus college-educated individuals they were at risk for skin cancer (OR, $0.46 ; 95 \% \mathrm{Cl}, 0.31-0.71$ ) or instructed them on how to examine their skin for signs of melanoma (OR, 0.40; $95 \% \mathrm{Cl}, 0.25-0.63$ ). HS-educated individuals were less likely to have received a physician skin examination within the year before diagnosis (OR, 0.54; $95 \% \mathrm{Cl}, 0.37-0.80$ ). CONCLUSIONS. Decreased melanoma risk perception and knowledge among low-SES individuals and decreased physician communication regarding skin examinations of these individuals may be key components of the consistently observed socioeconomic gradient in mortality. The current findings suggest the need to raise melanoma awareness among lower-SES patients and to increase physician awareness of socioeconomic disparities in clinical communication and care. Cancer 2012;118:4004-13. (C) 2011 American Cancer Society.

KEYWORDS: melanoma, screening, education, epidemiology, social class, detection.

\section{INTRODUCTION}

Individuals of lower socioeconomic status (SES), whether measured by educational level, income, or similar measures, have lower incidence rates of melanoma than those of higher SES. ${ }^{1}$ However, low SES has been associated repeatedly with thicker, more advanced melanoma at diagnosis and increased mortality. ${ }^{2-4}$ Given the increasing burden of thicker melanoma among lower-SES groups in the United States 5 and the potential to reduce overall morbidity/mortality by addressing socioeconomic disparities in survival, it is important to understand the mechanisms by which lower SES individuals develop more advanced disease.

Our analysis of 566 patients with newly diagnosed melanoma ${ }^{6}$ confirmed an association between melanoma thickness at diagnosis and low SES, as measured by education level. In our study, individuals with a high school (HS) or an associate degree were more likely to have thicker tumors $(>1 \mathrm{~mm})$ than those with a college degree or higher $(P=.0122)$.

Corresponding author: Alan C. Geller, RN, MPH, Harvard School of Public Health, Kresge Building Room 701 A, 677 Huntington Avenue, Boston MA 02215; Fax: (617); ageller@hsph.harvard.edu

${ }^{1}$ Department of Dermatology, Pigmented Lesion and Melanoma Program, Stanford University Medical Center and Cancer Institute, Stanford, California; ${ }^{2}$ Dermatology Service, Veterans Affairs Palo Alto Health Care System, Palo Alto, California; ${ }^{3}$ Departments of Dermatology, Otolaryngology, and Surgery, University of Michigan Medical School, Ann Arbor, Michigan; ${ }^{4}$ Department of Society, Human Development, and Health, Harvard School of Public Health, Boston, Massachusetts

Ricardo Pollitt's current address: Department of Dermatology, University of California, San Francisco, San Francisco, California

The sponsor had no role in the design or conduct of the study; in the collection, analysis, or interpretation of data; or in the preparation of the text, review, or approval of the article.

DOI: 10.1002/cncr.26706, Received: August 30, 2011; Revised: October 18, 2011; Accepted: October 21, 2011, Published online December 16, 2011 in Wiley Online Library (wileyonlinelibrary.com) 
However, few studies have explored the possible pathways between lower SES and more advanced melanoma. ${ }^{2,3,7,8}$ To this end, we surveyed 566 patients of mixed SES with recently diagnosed melanoma to explore 5 possible areas of importance in this relation: 1) attitudes and perceptions regarding melanoma; 2) basic knowledge about melanoma detection; 3) communication with physicians on issues of melanoma screening; 4) perceptions of barriers to health care access for melanoma screening and treatment; and 5) performance of physician screening and selfscreening, both of which were associated with thinner melanoma detection in the study cohort. ${ }^{6}$

\section{MATERIALS AND METHODS \\ Study Participants}

Approval for melanoma case ascertainment was obtained from the institutional review boards of Stanford University Medical Center (SUMC), Veterans Affairs Palo Alto Health Care System (VAPAHCS), and the University of Michigan (UM). Individuals aged $\geq 18$ years with a recent diagnosis of invasive, cutaneous melanoma $>2 \mathrm{~mm}$ and a random sample of one-third of individuals who had tumors $\leq 2 \mathrm{~mm}$ were surveyed within 3 months of diagnosis (by biopsy date) in the melanoma clinics of these institutions from May 17, 2006 through March 31, 2009, as previously described. ${ }^{9}$ Patients with in situ melanoma or mucosal, genital, perianal, or ocular primary melanoma were excluded. Overall, 566 of 719 patients (response rate, $79 \%$ ) completed the survey.

\section{Variable Definition}

The data obtained included patient demographics, education level, previous history of melanoma, and information on skin self-examination (SSE)-associated practices in the year before diagnosis. SES was assessed for the following education groups: 1) HS/general education degree or less, 2) associate or technical school degree, or 3) college graduate or more. ${ }^{10}$ Questionnaire items addressed 5 different areas: 1) attitudes and perceptions regarding melanoma, 2) awareness of melanoma and SSE, 3) health care access and physician screening for skin cancer, 4) physicianpatient communication, and 5) barriers to accessing/ receiving health care. All questions referred to the year before diagnosis except for questions on risk perception and physician-patient communication, which assessed life-long perceptions and communication patterns.

Attitudes and perceptions regarding melanoma were assessed by questions using a 5-point scale (extremely, quite, somewhat, a little, or not at all) asking about perceived risk and seriousness of melanoma. Awareness of melanoma was assessed using yes/no questions regarding knowledge about the asymmetry, borders (irregular), color (variegated), and diameter $(>6 \mathrm{~mm})(\mathrm{ABCD})$ rule for melanoma, the difference between melanoma and ordinary skin growths, and what kind of mole to look for when examining one's skin.

SSE within the last year was measured as described prevously ${ }^{9}$ by 1 ) the frequency of mole examination (never, every 1-2 months, every 6 months, or every year), 2) the use of a picture aid illustrating a melanoma tumor during SSE, and 3) whether patients routinely examined some or all of their skin (of 13 possible areas). Questions on health care use assessed where patients usually went when they were sick or needed health advice during the prior year, whether they had a physician they consulted regularly for routine care during this year, whether a physician examined their skin during any visits and, if so, whether the physician looked at their whole skin or just a particular lesion.

Physician-patient communication was assessed using yes/no questions regarding whether a physician ever talked with patients about skin cancer, instructed them on SSE, or told them they had atypical/dysplastic moles; whether they were at risk for skin cancer or to keep an eye on certain moles; and whether patients ever told a physician they had noticed a change in their moles. Questions on barriers to accessing/receiving health care asked about the cost and difficulty of consulting a dermatologist or obtaining health insurance covering a skin examination/ dermatology visit. If a patient, significant other, or friend first spotted the lesion that eventually was diagnosed as melanoma, then the patient answered questions about possible reasons for not consulting a physician right away (too time consuming, not concerned about the skin lesion, or more concerned about other health problems). These questions used a 5-point Likert response scale: strongly agree, agree, neither agree not disagree (neutral), disagree, or strongly disagree.

\section{Statistical Analysis}

We conducted multivariable logistic regression analyses to assess the effects of SES on the measures described above. Five-point scale certainty responses were dichotomized as quite/extremely versus somewhat/a little/not at all for analysis; Likert scale responses were dichotomized as strongly agree/agree versus neutral/disagree/strongly disagree. Multivariate linear regressions were used to 
Table 1. Socioeconomic Status as Assessed by Educational Level: Frequencies According to the Primary Confounders of Age, Sex, and Nevus Count

\section{Educational Level: No. of Patients (\%)}

\begin{tabular}{|c|c|c|c|c|}
\hline Confounder & $\begin{array}{l}\text { High School } \\
\text { Degree/GED or } \\
\text { Less, } N=198\end{array}$ & $\begin{array}{l}\text { Associate/ } \\
\text { Technical School } \\
\text { Degree, } N=97\end{array}$ & $\begin{array}{l}\text { Four-Year } \\
\text { College Degree } \\
\text { or More, } N=271\end{array}$ & $\begin{array}{l}\text { Total No., } \\
\mathrm{N}=566\end{array}$ \\
\hline \multicolumn{5}{|l|}{ Age, y } \\
\hline$\leq 40$ & $25(24.7)$ & $22(21.8)$ & $54(53.5)$ & 101 \\
\hline $41-50$ & 32 (31.4) & $25(24.5)$ & $45(44.1)$ & 102 \\
\hline $51-60$ & $47(35.1)$ & $26(19.4)$ & $61(45.5)$ & 134 \\
\hline $61-70$ & 40 (33.9) & 14 (11.9) & 64 (54.2) & 118 \\
\hline$>70$ & $54(48.7)$ & $10(9)$ & 47 (42.3) & 111 \\
\hline$P$ & & & & $.003^{a}$ \\
\hline \multicolumn{5}{|l|}{ Sex } \\
\hline Men & $121(35.1)$ & $51(14.8)$ & $173(50.1)$ & 345 \\
\hline Women & 77 (34.8) & $46(20.8)$ & $98(44.3)$ & 221 \\
\hline$P$ & & & & $.15^{\mathrm{a}}$ \\
\hline \multicolumn{5}{|l|}{ Nevus count } \\
\hline $0-20$ & $146(39)$ & $58(15.5)$ & $170(45.5)$ & 374 \\
\hline $21-50$ & $33(28.5)$ & $26(22.4)$ & $57(49.1)$ & 116 \\
\hline$>50$ & $19(25)$ & $13(17.1)$ & 44 (57.9) & 76 \\
\hline$P$ & & & & $.04^{\mathrm{a}}$ \\
\hline
\end{tabular}

Abbreviations: GED, general education degree.

${ }^{\text {a }} P$ values indicate the results from chi-square analyses.

calculate the odds ratios for "yes," "quite/extremely," or "strongly agree/agree" responses in lower educated versus college-educated patients.

Decisions to include covariates as potential confounders in the models were based on a significant association between the covariate and the independent (SES) and dependent (5 groups of patient characteristics) variables and either the statistical significance of the covariate's inclusion in the models or a change of $10 \%$ in the size of the SES measure's beta parameter upon inclusion of the covariate. Potential confounders examined included the above sociodemographic variables, previous history of melanoma, and histologic subtype. ${ }^{11}$ Analyses were conducted using the SAS statistical software package (version 9.2; SAS Institute, Inc., Cary, NC).

\section{RESULTS \\ Demographics}

Patients ranged in age from 18 years to 99 years, and 61\% of respondents were men. Approximately $95 \%$ of the sample was white. Slightly less than $48 \%$ of the sample had received a 4-year college degree or further education, 17\% had an associate or technical degree, and 35\% had an HS degree or less. All logistic regression models were adjusted by age, sex, and nevus count, as these covariates were identified as confounders of many of the associations examined. Table 1 indicates the frequency of educational level according to each of these 3 measures.

\section{Attitudes and Perceptions Regarding Melanoma}

Table 2 indicates how patients responded to questions regarding attitudes and perceptions about melanoma as well as the odds ratios (ORs) for answering "yes," "quite," or "extremely" by lower education versus college education calculated from logistic regression models. Lower education was strongly associated with higher odds that a patient had never thought of himself or herself as being at risk for melanoma (OR, for $\mathrm{HS}$ vs college education, 2.32; 95\% confidence interval [CI], 1.583.40). Similarly, patients with lower education had almost 3 times the odds of always having believed melanoma was not very serious (OR, 2.90; 95\% CI, 1.794.71) and were less than half as likely to have believed that their melanoma risk was higher than that of their peers (OR, 0.40; 95\% CI, 0.26-0.63). Lower education was associated with moderately increased worry about melanoma; patients with $\mathrm{HS}$ and associate degrees were $31 \%$ and $62 \%$ more likely, respectively, to have been "quite/extremely" worried about melanoma before diagnosis. 
Table 2. Attitude and Perception Variables: Frequencies by Education and Odds Ratios With 95\% Confidence Intervals for Lower Education Versus College Education Adjusted by Age, Sex, and Nevus Count

\section{No. of Answers}

Variable

I never thought of myself at melanoma risk

High school

Associate degree

College

I always thought melanoma was not very serious

High school

Associate degree

College

I thought I had a higher melanoma chance

compared with my peers

High school

Associate degree

College

was "quite" or "extremely" worried

about melanoma

High school

Associate degree

College
Yes/Quite/

Extremely
No/Not at All/A

Little/Somewhat
OR $(95 \% \mathrm{Cl})$ for

Answering Yes/Agree

for Lower Education

Versus College Education

Abbreviations: $\mathrm{Cl}$, confidence interval; OR, odds ratio.

\section{Knowledge About Melanoma Detection}

Lower education was strongly associated with reduced knowledge about melanoma detection (Table 3). Patients with HS and associate degrees were much less likely than college-educated patients to know about the $\mathrm{ABCD}$ rule for melanoma (OR, 0.34 [95\% CI, 0.23-0.52] and 0.58 [95\% CI, 0.36-0.94], respectively), to know the difference between melanomas and ordinary skin growths $(\mathrm{OR}, 0.26$ [95\% CI, 0.16-0.41] and 0.53 [95\% CI, 0.32-0.88], respectively), or to know what kind of mole to look for when examining their skin (OR, 0.39 [95\% CI, 0.250.59 ] and $0.5395 \%$ CI, 0.32-0.87], respectively).

\section{Skin Self-Examination}

Education was modestly associated with measures of SSE (Table 3). Compared with college-educated patients, HSeducated patients (but not those with associate degrees) had statistically significantly lower odds of routinely examining the skin on any of their body (OR, 0.52; 95\% CI, 0.32-0.83) and at least half of their body (OR, 0.67; 95\% CI, 0.46-0.97) or of ever having used a picture of melanoma as an aid in SSE (OR, 0.56; 95\% CI, 0.35-0.90). There was no significant association between education and whether patients carefully examined all of their moles at least yearly.

\section{Health Care Access and Physician Skin Examination}

Patients with an associate degree, but not those with an HS degree or less, were less likely (OR, 0.59; 95\% CI, $0.31-1.15)$ to have had a physician's office, clinic, or health center they regularly attended during the year before melanoma diagnosis compared with collegeeducated patients (Table 4), although the difference was not statistically significant. Patients with an HS or associate degree were about as likely as college-educated patients to have a health professional they consulted regularly for routine care, but they were significantly less likely to have received a skin examination for skin cancer from a health professional (OR, 0.54 [95\% CI, 0.37-0.80] and 0.52 [95\% CI, 0.32-0.87], respectively). There was no significant difference by educational level in the number of times patients visited a health care provider in the year before diagnosis ( $P=0.78$; data not shown).

Of the 258 patients who reported receiving a skin examination for cancer, 240 specified whether they received a complete skin examination or whether they 
Table 3. Knowledge About Melanoma and Skin Self-Examination Variables: Frequencies by Education and Odds Ratios With 95\% Confidence Intervals for Lower Education Versus College Education Adjusted by Age, Sex, and Nevus Count

\section{No. of Answers}

Variable

$\begin{array}{ll}\text { Yes/ } & \text { No/Disagree/ } \\ \text { Agree } & \text { Neutral }\end{array}$

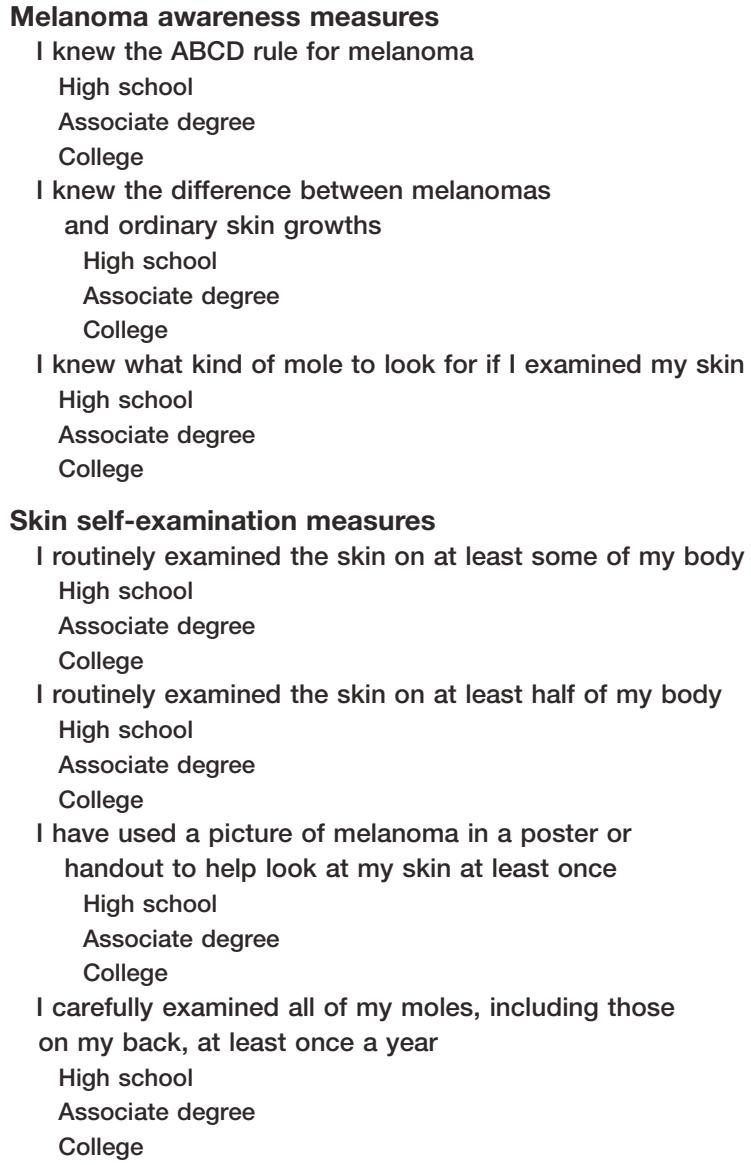

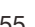

$\begin{array}{ll}132 & 0.34(0.23-0.52) \\ 56 & 0.58(0.36-0.94) \\ 123 & \text { Referent } \\ & \\ 159 & 0.26(0.16-0.41) \\ 68 & 0.53(0.32-0.88) \\ 153 & \text { Referent } \\ & \\ 142 & 0.39(0.25-0.59) \\ 63 & 0.53(0.32-0.87) \\ 144 & \text { Referent }\end{array}$

144 Referent
OR $(95 \% \mathrm{Cl})$ for Answering Yes/Agree for Lower Education Versus College Education

$0.52(0.32-0.83)$

$1.41(0.69-2.88)$

Referent

$0.67(0.46-0.97)$

$0.76(0.48-1.22)$

Referent

$0.56(0.35-0.90)$

$0.91(0.53-1.55)$

Referent

$0.73(0.50-1.08)$

0.89 (0.55-1.43)

Referent

Abbreviations: $A B C D$ rule, asymmetry, borders (irregular), color (variegated), and a greatest dimension $>6 \mathrm{~mm}$; $\mathrm{Cl}$, confidence interval; OR, odds ratio.

only had a particular lesion examined. Among these 240 patients, those with HS and associate degrees were significantly less likely than those with college degrees to report having received a complete skin examination $(\mathrm{OR}, 0.46$ [95\% CI, 0.31-0.68] and 0.50 [95\% CI, 0.30-0.82], respectively).

\section{Physician-Patient Communication}

Less educated patients were significantly less likely to report that a physician had ever talked with them about every melanoma-related issue assessed. Patients with an HS or associate education were significantly less likely than patients with a college education to have ever been told by a physician that they were at risk of skin cancer (OR, 0.46 [95\% CI, 0.31-0.71] and 0.56 [95\% CI, 0.3$0.95]$, respectively) or that they should keep an eye on certain moles (OR, 0.61 [95\% CI, 0.40-0.94] and 0.54 [95\% CI, 0.31-0.93], respectively) (Table 5). HSeducated patients also were significantly less likely than college-educated patients to have ever been told by a physician that they had atypical/dysplastic moles (OR, 0.44; 95\% CI, 0.25-0.79). Patients with an HS or associate education also had less than half the odds of ever having been instructed by a physician on how to look at their skin for signs of melanoma (OR, 0.40 [95\% CI, 0.250.63 ] and 0.43 [95\% CI, 0.24-0.77], respectively) or 
Table 4. Health Care Access and Physician Skin Examination Variables: Frequencies by Education for Odds Ratios With $95 \%$ Confidence Intervals by Lower Education Versus College Education Adjusted by Age, Sex, and Nevus Count

\section{No. of Answers}

Variable

$\begin{array}{ll}\text { Yes/ } & \text { No/Disagree/ } \\ \text { Agree } & \text { Neutral }\end{array}$

\author{
OR $(95 \% \mathrm{Cl})$ for \\ Answering Yes/ \\ Agree for Lower \\ Education Versus. \\ College Education
}

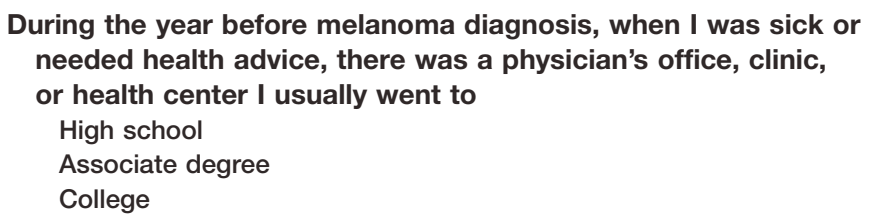

At the time, I had a physician who I saw regularly for routine care, such as a physical examination or check-up

During at least 1 visit, a physician examined my skin for cancer High school

Associate degree

College

During this skin examination, my physician looked at my whole skin and not just at a particular lesion

High school

Associate degree

College

$\begin{array}{lll}173 & 20 & 1.02(0.55-1.89) \\ 75 & 18 & 0.59(0.31-1.15) \\ 240 & 31 & \text { Referent }\end{array}$

$\begin{array}{lll}161 & 33 & 0.90(0.54-1.51) \\ 72 & 20 & 0.90(0.49-1.66) \\ 222 & 49 & \text { Referent }\end{array}$

$\begin{array}{lll}81 & 110 & 0.54(0.37-0.80\end{array}$

$\begin{array}{lll}33 & 58 & 0.52(0.32-0.87)\end{array}$

$144 \quad 121 \quad$ Referent

$\begin{array}{lll}36 & 36 & 0.46(0.31-0.68) \\ 17 & 13 & 0.50(0.30-0.82) \\ 94 & 44 & \text { Referent }\end{array}$

Abbreviations: $\mathrm{Cl}$, confidence interval; OR, odds ratio.

having spoken with their physician about skin cancer at all (OR, 0.43 [95\% CI, 0.29-0.63] and 0.46 [95\% CI, 0.28$0.76]$, respectively). Those without a college degree were not significantly less likely to have ever noticed a change in any of their moles (data not shown). However, among patients who had ever noticed such a change $(\mathrm{N}=310)$, patients who had an HS degree were significantly less likely to have ever told a physician about it compared with those who had a college education (OR, 0.38; 95\% CI, 0.19-0.76).

\section{Barriers to Accessing/Receiving Health Care}

Three variables assessed possible reasons patients may have had for not consulting a dermatologist for a skin examination before their diagnosis of melanoma (Table 6). Cost was significantly more likely to be an issue for patients who had associate degrees compared with those who had college degrees (OR, 2.18; 95\% CI, 1.01-4.69); there were no other significant associations between education and responses to these variables.

Other variables assessed possible reasons for not consulting a physician after a patient or spouse/significant other $(\mathrm{N}=390)$ spotted a skin lesion that eventually was diagnosed as melanoma. Compared with college-educated patients, patients with HS and associate degrees were significantly more likely to report having a competing concern about other health problems (OR, $3.40[95 \% \mathrm{CI}$, 1.69-6.84] and 3.59 [95\% CI, 1.60-8.04], respectively). No other clear associations were observed.

\section{DISCUSSION}

Individuals of lower SES experience later stage melanoma at diagnosis, higher case-fatality rates, and decreased survival. ${ }^{3,8,12,13}$ Recent studies have revealed disproportionate rates of advanced disease among less educated individuals and those living in poor areas, among Medicaid patients in California, and in Massachusetts residents living in lower SES census tracts or zip codes, independent of sociodemographic variables, comorbidities, and tumor characteristics. ${ }^{3,8,13-15}$

We sought to understand why individuals of lower SES have higher rates of thicker, more advanced melanoma. We hypothesized that differences in perceptions 
Table 5. Physician-Patient Communication Variables: Frequencies by Education and Odds Ratios With $95 \%$ Confidence Intervals for Lower Education Versus College Education Adjusted by Age, Sex, and Nevus Count

\section{No. of Answers}

Variable

$\begin{array}{ll}\text { Yes/ } & \text { No/Disagree/ } \\ \text { Agree } & \text { Neutral }\end{array}$

OR $(95 \% \mathrm{Cl})$ for

Answering Yes/Agree

for Lower Education

Versus College Education

Ever told by a physician that I was at risk for skin cancer

\author{
High school \\ Associate degree \\ College \\ Ever told by a physician that I have atypical \\ or dysplastic moles \\ High school \\ Associate degree \\ College
}

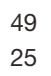

108

\section{Ever told by a physician to keep an eye on certain moles}

High school

Associate degree

College

Ever instructed or given materials on how to

look at my skin for signs of melanoma

High school

Associate degree

College

Ever talked with my physician about skin cancer

High school

Associate degree

College

Ever noticed a change in any of my moles

High school

Associate degree

College

Ever told a physician that a mole or moles had changed ( $N=310$; only answered if had previously noticed a change in a mole)

High school

Associate degree

College

$\begin{array}{ll}143 & 0.46(0.31-0.71) \\ 70 & 0.56(0.33-0.95) \\ 158 & \text { Referent }\end{array}$

165

81

211

$0.44(0.25-0.79)$

$0.69(0.35-1.35)$

Referent

$0.61(0.40-0.94)$

$0.54(0.31-0.93)$

Referent

$0.40(0.25-0.63)$

$0.43(0.24-0.77)$

Referent

$0.43(0.29-0.63)$

$0.46(0.28-0.76)$

Referent

$0.82(0.56-1.21)$

$0.76(0.47-1.24)$

Referent

$0.38(0.19-0.76)$

$0.65(0.28-1.54)$

Referent

Abbreviations: $\mathrm{Cl}$, confidence interval; $\mathrm{OR}$, odds ratio.

about melanoma, basic knowledge about melanoma detection, patient-physician communication, and physician and self-screening may play a part. By examining the responses from a mix of patients who were diagnosed with thin and thick melanomas, we can begin to describe a pattern among individuals with lower SES that involves minimal perception of the risks of melanoma and less awareness of melanoma's early warning signs, is marked by less communication from physicians regarding melanoma risk factors and screening/detection, and culminates in far fewer SSEs and physician skin examinations (PSEs).
Greater knowledge about melanoma has been associated with thinner tumors ${ }^{16}$ and shorter delays from lesion discovery to diagnosis. ${ }^{17}$ We observed striking educational differences in risk perception and knowledge about melanoma; less educated patients were far less likely to 1) perceive themselves at risk for melanoma, 2) understand that melanoma is serious, or 3) know about the $\mathrm{ABCD}$ rule or about differences between melanoma and ordinary skin growths. A 1995 national survey indicating that only $12 \%$ of Americans with less than HS education knew that melanoma was a type of skin cancer also speaks to strong educational disparities in awareness. ${ }^{18}$ 
Table 6. Barriers to Health Care Variables: Frequencies by Education and Odds Ratios With 95\% Confidence Intervals for Lower Education Versus College Education Adjusted by Age, Sex, and Nevus Count

\section{No. of Answers}

Variable and Educational Level

$\begin{array}{ll}\text { Agree/ } & \text { Disagree/ } \\ \text { Strongly } & \text { Strongly } \\ \text { Agree } & \text { Disagree } \\ & \text { /Neutral }\end{array}$

OR $(95 \% \mathrm{Cl})$ for Answering Yes/Agree for Lower Education Versus College Education
$1.41(0.69-2.87)$

$2.18(1.01-4.69)$

Referent

$1.07(0.48-2.40)$

$1.60(0.67-3.83)$

Referent

$1.61(0.74-3.53)$

$1.86(0.76-4.55)$

Referent

Possible reasons for not seeing a physician after patient or significant other spotted the unusual mole eventually diagnosed as melanoma (only answered if patient or significant other first spotted the mole; $\mathbf{N}=390$ )

I did not have time to go to physician High school Associate degree College

I was concerned about other health problems High school

Associate degree

College

I was not really too concerned about the mole

High school

Associate degree

College

$\begin{array}{ll}102 & 0.98(0.47-2.04) \\ 57 & 0.70(0.28-1.78) \\ 148 & \text { Referent } \\ & \\ 87 & 3.40(1.69-6.84) \\ 49 & 3.59(1.60-8.04) \\ 157 & \text { Referent } \\ & \\ 76 & 1.10(0.66-1.83) \\ 41 & 1.14(0.62-2.10) \\ 117 & \text { Referent }\end{array}$

Abbreviations: $\mathrm{Cl}$, confidence interval; OR, odds ratio.

Media outreach and public attention to early detection of melanoma (as opposed to sun protection) is relatively recent compared with what the public has learned about smoking and breast cancer. Lessons from public health efforts for tobacco control are instructive for skin cancer advocates. Immediately after the Surgeon General's landmark 1964 report on tobacco, most educated women immediately reduced their smoking in contrast to the least educated, who actually increased their smoking rates. ${ }^{19}$ Education and awareness of good health behaviors may have important interactive effects ${ }^{20}$; smoking behavior among more educated individuals was altered more in response to knowledge than in those with less education. We observed a similar combination of decreased perceived risk and decreased knowledge about melanoma among the less educated in our study.

In a population-based, case-control study in Queensland, Aitken et al observed that higher education was associated with increased whole-body SSE. ${ }^{21}$ We observed a modest association between lower SES and less frequent SSE. HS-educated patients were less likely to frequently examine their skin or to use a picture aid to assist with SSE. ${ }^{9,22-24}$ The importance of SSE in preventing more advanced melanoma remains unclear, and further assessment of the role of SSE as a possible link between lower SES and more advanced disease is warranted.

Youl et al reported that higher education was associated significantly $(P<.001)$ with increased rates of 
clinical skin examination in the Queensland study. ${ }^{8}$ We confirmed that association, observing that HS-educated patients were approximately half as likely to receive a PSE in the year before diagnosis compared with college-educated patients, and HS-education patients were even less likely to receive a whole-body skin examination. Our data demonstrate a link between lower SES and the decreased likelihood of receiving a PSE, which is associated with thinner tumors in men aged $>60$ years. ${ }^{6}$ This suggests the importance of PSE as a possible link between lower SES and more advanced melanoma.

Effective physician-patient communication includes shared decision making, comprehension of medical information, mutual comfort, and patient disclosure. ${ }^{25} \mathrm{~A}$ systematic review indicated that higher SES is associated repeatedly with increased overall physician-patient communication and provision of information. ${ }^{26,27-29}$ Independent of patient behavior, differences in physicians' engagement with patients have been related directly to patients' levels of education. ${ }^{30}$

We observed that physicians were much less likely to warn less educated patients about melanoma risk factors or to discuss issues regarding melanoma screening and detection with them. Because less educated patients also were much less likely to perceive melanoma as serious or to have basic knowledge regarding melanoma, this lack of communication by physicians is particularly concerning. Patients of lower SES also were less likely ever to have told a physician that a mole had changed, suggesting that suboptimal physician-patient communication was bidirectional.

Little work has been done examining SES-specific barriers to skin cancer screening, although socioeconomic disparities in screening for other cancers (fecal occult blood testing, mammography, and prostate-specific antigen screening) are well documented. Less educated patients are less likely to be aware of the need for screening or to discuss screening with physicians, and physicians may be less likely to perceive these patients as willing to participate in screening or to recommend screening to them. ${ }^{31-34}$ We did not observe that less educated individuals perceived greater potential barriers to accessing screening than more educated individuals. Once patients had discovered an unusual/concerning mole, however, less educated patients were far more likely to report that competing health concerns may have been a reason for not consulting a physician regarding the skin lesion. These results suggest a lack of awareness of the seriousness of a melanoma diagnosis and strengthen our findings described above that individuals of lower SES may be significantly less likely to conceive of skin lesions and melanoma as entities with serious potential health impact.

Our behavioral data were self-reported, raising possible concerns about potential recall accuracy and bias. Given the severity of a melanoma diagnosis, the risk of recall bias may be higher in our study population. Our data are cross-sectional; thus, we were unable to prospectively assess the impact of SES on melanoma risk factors and outcomes. Future prospective studies are needed to further delineate the associations we describe here. It is possible that patient factors particular to this study (ie, proximity to an academic center) may have favored all respondents, regardless of educational status. SES was assessed only through education level, and, unfortunately, other important facets of SES (eg, occupational status, income) were unavailable. Subgroup analysis by age and sex was not possible with these data given the nature and number of our variables. In addition, it is reasonable to speculate that individuals with college degrees had stronger communication patterns because of a greater likelihood of having a regular dermatologist, although this information was not assessed. However, college-educated patients were no more likely to have had their melanoma diagnosed by a dermatologist than other patients.

Given the disproportionate burden of advanced melanoma at diagnosis and higher case fatality among individuals of lower SES, new public and professional education strategies are required. Our findings suggest the need for new public education campaigns to raise awareness of melanoma risk and to increase basic knowledge about melanoma screening and detection among individuals of lower SES. In addition, professional educational efforts are needed to improve physician communication to lower SES individuals about melanoma risk factors, prevention strategies, and early detection and to increase physician skin screening in this group.

\section{FUNDING SOURCES}

This work was supported by Merck and Company, Inc. Dr. Pollitt's work was supported in part by the Stanford Medical Scholars Research Program during his medical school tenure.

\section{CONFLICT OF INTEREST DISCLOSURES}

The authors made no disclosures.

\section{REFERENCES}

1. Clegg LX, Reichman ME, Miller BA, et al. Impact of socioeconomic status on cancer incidence and stage at diagnosis: selected findings from the Surveillance, Epidemiology, and 
End Results: National Longitudinal Mortality Study. Cancer Causes Control. 2009;20:417-435.

2. Zell JA, Cinar P, Mobasher M, Ziogas A, Meyskens FL Jr, Anton-Culver H. Survival for patients with invasive cutaneous melanoma among ethnic groups: the effects of socioeconomic status and treatment. J Clin Oncol. 2008;26:66-75.

3. Ortiz CA, Goodwin JS, Freeman JL. The effect of socioeconomic factors on incidence, stage at diagnosis and survival of cutaneous melanoma. Med Sci Monit. 2005;11:RA163RA172.

4. Van Durme DJ, Ferrante JM, Pal N, Wathington D, Roetzheim RG, Gonzalez EC. Demographic predictors of melanoma stage at diagnosis. Arch Fam Med. 2000;9:606-611.

5. Linos E, Swetter SM, Cockburn MG, Colditz GA, Clarke CA. Increasing burden of melanoma in the United States. J Invest Dermatol. 2009;129:1666-1674.

6. Swetter SM, Pollitt RA, Johnson MJ, Brooks DR, Geller AC. Behavioral determinants of successful early melanoma detection: role of self and physician skin examination. Cancer. 2012;118:3725-3734.

7. Geller AC, Johnson TM, Miller DR, Brooks KR, Layton CJ, Swetter SM. Factors associated with physician discovery of early melanoma in middle-aged and older men. Arch Dermatol. 2009;145:409-414.

8. Youl PH, Baade PD, Parekh S, English D, Elwood M, Aitken JF. Association between melanoma thickness, clinical skin examination and socioeconomic status: results of a large population-based study. Int J Cancer. 2011;128:2158-2165.

9. Pollitt RA, Geller AC, Brooks DR, Johnson TM, Park ER, Swetter SM. Efficacy of skin self-examination practices for early melanoma detection. Cancer Epidemiol Biomarkers Prev. 2009; 18:3018-3023.

10. Liberatos P, Link BG, Kelsey JL. The measurement of social class in epidemiology. Epidemiol Rev. 1988;10:87-121.

11. Kleinbaum DG, Kupper LK, Muller KE, Nizam A. Applied Regression Analysis and Other Multivariable Methods. 3rd ed. Washington, DC: Brooks/Cole Publishing Company; 1998.

12. Aitken JF, Elwood M, Baade PD, Youl P, English D. Clinical whole-body skin examination reduces the incidence of thick melanomas. Int J Cancer. 2010;126:450-458.

13. Reyes-Ortiz CA, Goodwin JS, Freeman JL, Kuo YF. Socioeconomic status and survival in older patients with melanoma. J Am Geriatr Soc. 2006;54:1758-1764.

14. Geller AC, Miller DR, Lew RA, Clapp RW, Wenneker $\mathrm{MB}$, Koh HK. Cutaneous melanoma mortality among the socioeconomically disadvantaged in Massachusetts. Am J Public Health. 1996;86:538-543.

15. Pollitt RA, Clarke CA, Shema SJ, Swetter SM. California Medicaid enrollment and melanoma stage at diagnosis: a population-based study. Am J Prev Med. 2008;35:7-13.

16. Baumert J, Plewig G, Volkenandt M, Schmid-Wendtner $\mathrm{MH}$. Factors associated with a high tumour thickness in patients with melanoma. Br J Dermatol. 2007;156:938-944.

17. Temoshok L, DiClemente RJ, Sweet DM, Blois MS, Sagebiel RW. Factors related to patient delay in seeking medical attention for cutaneous malignant melanoma. Cancer. 1984; 54:3048-3053.

18. Miller DR, Geller AC, Wyatt SW, et al. Melanoma awareness and self-examination practices: results of a United States survey. J Am Acad Dermatol. 1996;34:962-970.

19. Aizer A, Stroud L. Education, Knowledge and the Evolution of Disparities in Health: Working Paper 15840. Cambridge, MA: National Bureau of Economic Research; 2010.

20. Kenkel DS. Health behavior, health knowledge, and schooling. J Political Econ. 1991;99:287-305.

21. Aitken JF, Janda M, Lowe JB, et al. Prevalence of whole-body skin self-examination in a population at high risk for skin cancer (Australia). Cancer Causes Control. 2004;15:453-463.

22. Collins M, Kelsberg G, Safranek S, Van Durme DJ. Clinical inquiries. Is training patients in self-examination an effective way to screen for melanoma? J Fam Pract. 2008;57:336-337.

23. Geller AC, Swetter SM, Brooks K, Demierre MF, Yaroch AL. Screening, early detection, and trends for melanoma: current status (2000-2006) and future directions. J Am Acad Dermatol. 2007;57:555-572; quiz 573-556.

24. Berwick M, Begg CB, Fine JA, Roush GC, Barnhill RL. Screening for cutaneous melanoma by skin self-examination. J Natl Cancer Inst. 1996;88:17-23.

25. Teutsch C. Patient-doctor communication. Med Clin North Am. 2003;87:1115-1145.

26. Willems S, De Maesschalck S, Deveugele M, Derese A, De Maeseneer J. Socio-economic status of the patient and doctor-patient communication: does it make a difference? Patient Educ Couns. 2005;56:139-146.

27. Street RL Jr, Haidet P. How well do doctors know their patients? Factors affecting physician understanding of patients' health beliefs. J Gen Intern Med. 2011;26:21-27.

28. Street RL Jr, Gordon HS, Ward MM, Krupat E, Kravitz RL. Patient participation in medical consultations: why some patients are more involved than others. Med Care. 2005;43:960-969.

29. Gage E. Examining the most relevant conceptualization of the socioeconomic status construct for cancer research [serial online]. Cancer Nurs. 2010;33:E1-E9.

30. Street RL Jr. Gender differences in health care providerpatient communication: are they due to style, stereotypes, or accommodation? Patient Educ Couns. 2002;48:201-206.

31. Ye J, Xu Z, Aladesanmi O. Provider recommendation for colorectal cancer screening: examining the role of patients' socioeconomic status and health insurance. Cancer Epidemiol. 2009;33:207-211.

32. Doubeni CA, Laiyemo AO, Reed G, Field TS, Fletcher RH. Socioeconomic and racial patterns of colorectal cancer screening among Medicare enrollees in 2000 to 2005. Cancer Epidemiol Biomarkers Prev. 2009;18:2170-2175.

33. McCaffery K, Wardle J, Nadel M, Atkin W. Socioeconomic variation in participation in colorectal cancer screening. J Med Screen. 2002;9:104-108.

34. Wardle J, McCaffery K, Nadel M, Atkin W. Socioeconomic differences in cancer screening participation: comparing cognitive and psychosocial explanations. Soc Sci Med. 2004;59:249-261. 